Applied Remote Sensing

\title{
Monitoring bidecadal development of urban agglomeration with remote sensing images in the Jing-Jin-Tang area, China
}

Linlin Lu

Huadong Guo

Cuizhen Wang

Martino Pesaresi

Daniele Ehrlich 


\title{
Monitoring bidecadal development of urban agglomeration with remote sensing images in the Jing-Jin-Tang area, China
}

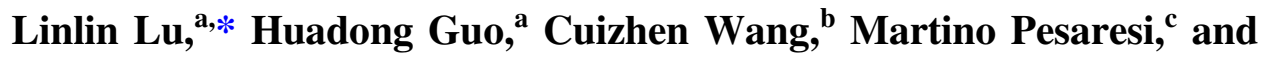 \\ Daniele Ehrlich ${ }^{\mathrm{c}}$ \\ ${ }^{a}$ Chinese Academy of Sciences, Institute of Remote Sensing and Digital Earth, \\ Key Laboratory of Digital Earth Science, 100094 Beijing, China \\ ${ }^{b}$ University of South Carolina, Department of Geography, Columbia, South Carolina 29208 \\ ${ }^{\mathrm{c} J o i n t ~ R e s e a r c h ~ C e n t r e, ~ E u r o p e a n ~ C o m m i s s i o n, ~ I n s t i t u t e ~ f o r ~ t h e ~ P r o t e c t i o n ~ a n d ~}$ \\ Security of the Citizen, I-21027 Ispra, Italy
}

\begin{abstract}
As an important urban agglomeration of China, the Jing-Jin-Tang area has experienced intense urbanization since the 1980s. This study explores the spatiotemporal dynamics of urban areas in this region using multitemporal Landsat images. An enhanced built-up (BU) index method was applied to extract BU areas with an overall accuracy ranging from $75 \%$ to $91.35 \%$. Seven spatial metrics were used to discern urban growth patterns at city and county levels. The results indicate that all cities witnessed a rapid growth of BU areas with different spatial patterns. Beijing has been aggregating since the 1990s and a large homogeneous urban patch has formed. The construction and development of metropolitan Beijing and Tianjin started in the early 1980s and became almost fully developed by the end of 1990. Tangshan, like many medium-sized cities in China, is still enduring a development process with an accelerating pace. The metropolitan areas of Beijing and Tianjin have been greatly developed with BU densities exceeding 90\% since 2000, compared with Tangshan's 55\% in 2010. These results provide spatial information on the evolution of urban extent in the period of 1990s to 2010s in this region. (C) The Authors. Published by SPIE under a Creative Commons Attribution 3.0 Unported License. Distribution or reproduction of this work in whole or in part requires full attribution of the original publication, including its DOI. [DOI: 10.1117/1.JRS.8.084592]
\end{abstract}

Keywords: urban agglomeration; Landsat; built-up; urbanization.

Paper 13335SS received Aug. 29, 2013; revised manuscript received Jan. 26, 2014; accepted for publication Jan. 28, 2014; published online Feb. 18, 2014.

\section{Introduction}

Urbanization can be defined as the territorial and socioeconomic progress of an area that includes a general transformation of land cover/use categories from undeveloped to developed. ${ }^{1}$ In recent years, urban growth has exploded in developing countries all over the world. China has been undergoing an accelerated process of urbanization, manifested by urban population growth, expansion of existing cities, and the rapid emergence of new city centers. China had 132 cities in 1949 and 655 in 2004, according to census data. ${ }^{2}$

The Beijing-Tianjin-Tangshan (a.k.a. Jing-Jin-Tang) urban agglomeration is mainly composed of three adjacent cities: Beijing, Tianjin, and Tangshan in northern China. It is located at the heart of the Bohai Economic Rim, and plays a vital role in the nation's economic growth. ${ }^{3}$ This area has experienced intense urbanization since the national economic reform of the late 1980s. The rapid growth of built-up (BU) areas has brought great pressure to local environment and has led to serious environmental problems such as water shortage, air/water pollution, and vegetation degradation, especially in overpopulated areas. Air pollution results in significant negative health impacts on the large population in cities like Beijing. ${ }^{4}$ Dumping solid waste on the

*Address all correspondence to: Linlin Lu, 1llu@ ceode.ac.cn 
outskirts of cities also consumes a significant amount of arable land. ${ }^{5}$ Up-to-date information on urban extent and change is useful for environmental impact assessment and strategic planning for appropriate allocation of services and infrastructure within towns and cities in this region.

Remote sensing provides synoptic views from space and continuous observations with high temporal and spatial resolutions. It offers the capacity for dynamic monitoring of urban agglomerations and has been proved to be an effective tool to map land use and changes. Many previous studies in urban extent mapping have been based on the use of images at medium spatial resolutions such as the 30-m Landsat Thematic Mapper (TM) and Enhanced Thematic Mapper Plus $\left(\right.$ ETM+) images. ${ }^{6-9}$ In particular, special attention has been given to large cities and urban agglomerations at the global level. ${ }^{10-14}$ For example, Weng produced land use and land cover maps for 1989, 1994, and 1997 from Landsat TM images and analyzed the process of urban agglomerations of the Zhujiang Delta, China. ${ }^{10}$ Griffiths et al. developed an approach to mapping urban growth from multisensor data and applied it to the Dhaka megacity region in Bangladesh between 1990 and 2006. ${ }^{11}$ Pesaresi et al. tested an automatic procedure to extract the presence of BU areas in Ikonos and QuickBird high-resolution satellite imagery of large cities globally. ${ }^{12}$ Taubenböck et al. monitored urbanization of 27 megacities using a time series of Landsat scenes with temporal intervals of 10 years in the past 40 years. ${ }^{14}$ Although the urbanization process of specific cities was analyzed with remote sensing data, ${ }^{3,15,16}$ decadal changes of urban areas in different geographical regions have not been systematically assessed and compared for the entire Jing-Jin-Tang area.

Urban lands are complex, featuring spatial and spectral heterogeneity in composition of multifold artificial and natural surface types. ${ }^{17}$ Urban landscape monitoring with Landsat presents many challenges, which include the spectral mixing of diverse land cover types within pixels and spectral confusion with other land cover types such as fallow agricultural fields. ${ }^{18}$ A number of classification methods have been developed to map the urban landscape using Landsat imagery. One general type involves the thresholding of indices such as the commonly applied vegetation indices ${ }^{19,20}$ and customized BU indicators to segregate urban from nonurban lands. Zha et al. proposed the normalized difference BU index (NDBI) to automatically map urban BU areas. ${ }^{21}$ The method takes advantage of the unique spectral responses of BU areas and other land covers, and was improved by He et al. with a semiautomatic segmentation approach. ${ }^{22}$

In addition to classification maps, spatial metrics are utilized to quantitatively analyze and describe the spatiotemporal patterns of change in urban areas. ${ }^{23,24}$ Adopted from landscape ecology and termed as landscape metrics, ${ }^{25}$ spatial metrics are measurements derived from digital analysis of thematic categorical maps exhibiting spatial heterogeneity at a specific scale and resolution. ${ }^{23}$ They can be computed as patch-based indices (e.g., size, shape, edge length, patch, density, and fractal dimension). Recent studies demonstrated that these indices can be used to quantify the spatiotemporal patterns of urban change by computing them directly from thematic maps, ${ }^{26,27}$ The relationship between spatial distribution of an urban area and its change process can be visualized. Numerous landscape ecology programs are designed to compute a wide variety of landscape metrics. One of them, FRAGSTATS, has been developed and disseminated to the public by the Landscape Ecology Lab at the University of Massachusetts since $1995 .^{28}$ The FRAGSTATS metric program was employed in this study to evaluate the urban evolution of the Jing-Jin-Tang agglomeration.

The main goal of this study was to map urban areas and to interpret their changes in the JingJin-Tang urban agglomeration from 1990 to 2010 with multitemporal Landsat data. The urban area was extracted using an improved BU index method from TM and ETM+ images. Several spatial metrics were then generated to quantify and analyze urbanization patterns of the entire region and individual cities.

\section{Study Area and Dataset}

\subsection{Study Area}

Our research focuses on the urban agglomeration area in the Bohai Rim $\left(38^{\circ} 30^{\prime} \mathrm{N}\right.$ to $41^{\circ} 8^{\prime} \mathrm{N}$; $115^{\circ} 17^{\prime} \mathrm{E}$ to $119^{\circ} 30^{\prime} \mathrm{E}$ ), covering approximately $42,000 \mathrm{~km}^{2}$. It includes Beijing and Tianjin municipalities, a medium-sized city of Tangshan, and several small cities belonging to 


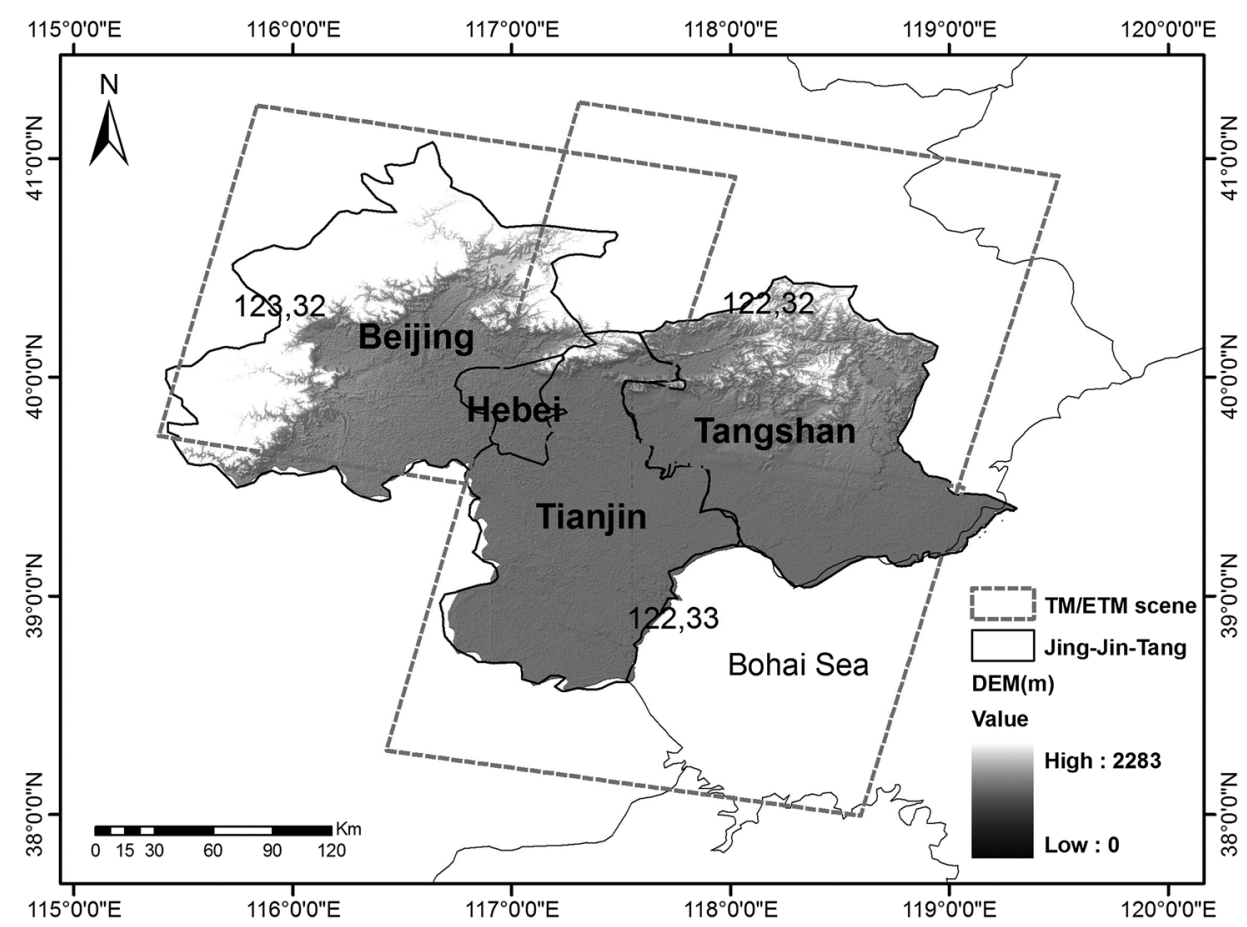

Fig. 1 Elevation map of the Jing-Jin-Tang urban agglomeration. The area is covered in three $\mathrm{TM} / \mathrm{ETM}+$ scenes.

Hebei Province in the east of Beijing. The Jing-Jin-Tang urban agglomeration is surrounded by the Yan Mountains in the north and the Taihang Mountains in the west (Fig. 1). Most of the urban areas are located in plain areas between 20 and $60 \mathrm{~m}$. The region has a semihumid warm-temperate monsoon climate with an average yearly temperature of $11.7^{\circ} \mathrm{C}$ and annual rainfall of $700 \mathrm{~mm}$. Agricultural lands dominate the suburban environment and winter wheat and maize are the main crops.

Beijing, the capital city, is among the most developed cities in China. It is the country's political, cultural, and educational center and also a major transportation hub, with dozens of railways and roads passing through. Tianjin, a municipality under direct administration of the central government, ranked sixth in terms of urban population in China. As a dual-core city, Tianjin is divided into the old city and the "Binhai New Area" (BNA). Tangshan is a prefecture-level city in Hebei Province and an important heavy-industry city in North China. Each city is divided into county-level administrative subdivisions. All the subdivisions can be categorized into three groups: urban district, suburban district, and rural district, by their distance from the city center. Urban districts are located in the inner city. Suburban districts refer to outlying areas of a city and have a lower BU density than the inner city. Rural districts are located far from the inner city and are less urbanized with a low population density. These three cities experienced rapid urbanization in the last 20 years as reported in national census data in 1990, 2000, and 2010 (Table 1). Megacities are defined as urban agglomerations with at least 10 million inhabitants. ${ }^{29}$ The metropolitan areas of Beijing and Tianjin can thus be treated as megacities (Table 1). The total population of Jing-Jin-Tang reached 40.127 million in 2010.

\subsection{Dataset}

The Landsat multitemporal dataset was used to measure urban development in the study area. The Landsat data have been continuously available since 1972, featuring geometric resolutions of $79 \mathrm{~m}$ (multispectral scanner since 1972), $30 \mathrm{~m}$ (TM since 1982), and $15 \mathrm{~m}$ (panchromatic band of the ETM+ since 1999). These long-term data records provide an extended time series that are superior to other high-resolution sensors. ${ }^{33,34}$ Moreover, the relatively high temporal resolution (16 days) and the sensor's wide swath $(185 \mathrm{~km})$ facilitate the depiction of extended areas of urban agglomerations. 
Table 1 Population growth of the Jing-Jin-Tang urban agglomeration in the past 20 years (in thousands).

\begin{tabular}{lccc}
\hline \hline City & 1990 & 2000 & 2010 \\
\hline Beijing & 10,819 & 13,819 & 19,612 \\
Tianjin & 8785 & 10,009 & 12,938 \\
Tangshan & 6628 & 7120 & 7577 \\
Total & 26,232 & 30,948 & 40,127 \\
\hline
\end{tabular}

Source: National Bureau of Statistics of China (Refs. 30-32).

The ETM+ and TM data in this study were acquired from the remote sensing data sharing platform of the Center for Earth Observation and Digital Earth, Chinese Academy of Sciences (http://ids.ceode.ac.cn/) and the global land cover facility, University of Maryland (ftp:// ftp.glcf.umd.edu/glcf/Landsat/). Three Landsat footprints (path/row 122/32, 122/33, and 123/ 32) cover the entire urban agglomeration region (Fig. 1). We used images acquired in JulySeptember, since bare soils were covered by vigorous vegetation and could be better differentiated from BU areas during this period. Particularly, images under cloud-free conditions were manually selected with scene 1 to 3,4 to 6 , and 7 to 9 representing the development of urban areas in earlier 1990s, 2000s, and 2010s respectively (Table 2). All TM/ETM+ images listed above were geometrically rectified and mosaicked. Atmospheric correction was conducted with atmospheric and topographic correction software. ${ }^{35}$

\section{Methodology}

\subsection{BU Area Extraction}

Urban areas and their decadal extension are the major concern of this study. Here, we categorized the land surface types of the study region into BU and nonurbanized areas, which could be delineated based on the difference of their spectral features. To simplify the process, a water mask was built to eliminate water bodies by visual interpretation of satellite images. Water bodies include rivers, lakes, and ponds. Human settlements located higher than $60 \mathrm{~m}$ in elevation were also eliminated for considering the large uncertainty of BU area detection over rugged

Table 2 List of Landsat data used in this study.

\begin{tabular}{lccc}
\hline \hline Scene No. & Type of imagery & Date & Path/row \\
\hline 1 & Landsat 5 TM & July 30, 1992 & $122 / 32$ \\
2 & Landsat 5 TM & September 30, 1991 & $122 / 33$ \\
3 & Landsat 5 TM & September 7, 1992 & $123 / 32$ \\
4 & Landsat 7 ETM+ & August 11, 1999 & $122 / 32$ \\
5 & Landsat 7 ETM+ & September 1, 2001 & $122 / 33$ \\
6 & Landsat 7 ETM+ & August 2, 1999 & $123 / 32$ \\
7 & Landsat 5 TM & September 12, 2008 & $122 / 32$ \\
8 & Landsat 5 TM & September 12, 2008 & $122 / 33$ \\
9 & Landsat 5 TM & September 22, 2009 & $123 / 32$ \\
\hline \hline
\end{tabular}


surfaces and steep terrains. We adopted an enhanced difference BU index to extract BU areas from other land cover types.

During the time of image acquisitions in July-September, nonurbanized areas were natural vegetation or agricultural lands covered with healthy, green plants in their growing season. Therefore, these areas were characterized by high values of the normalized difference vegetation index: ${ }^{21,22}$

$$
\mathrm{NDVI}=\frac{\text { Band } 4-\text { Band } 3}{\text { Band } 4+\text { Band } 3}
$$

where Band 4 and Band 3 represent the spectral reflectance of the near-infrared and red bands, respectively.

BU areas are composed of manmade constructions such as buildings and paved roads where green cover is limited. Therefore, these areas often reach low NDVI values. Rather, they are characterized with slightly higher reflectance in the short-wave infrared band than that in near-infrared. Contrarily, vegetated nonurbanized areas often experience a rapid decrease from near-infrared to short-wave infrared, especially for vigorous vegetation with high leaf water content. ${ }^{36}$ The NDBI could be calculated as ${ }^{21}$

$$
\mathrm{NDBI}=\frac{\text { Band } 5-\text { Band } 4}{\text { Band5 }+ \text { Band } 4}
$$

where Band5 is the spectral reflectance of the short-wave infrared band.

We then define the BU index:

$$
\mathrm{BU}=\mathrm{NDBI}-\mathrm{NDVI}
$$

Apparently, BU areas have large BU values while the nonurbanized areas have small ones. An optimal threshold method is applied to assign each pixel into the corresponding class. For each scene, a specific threshold is defined with randomly selected training samples. To simplify the process, NDVI, NDBI, and BU were normalized into $(0,255)$ using linear stretch.

\subsection{Spatial Metric Analysis}

Urban areas are characterized with complex spatial heterogeneity with a mixture of various land cover types. Urban growth in different cities may follow different sprawling patterns. It can be linear along traffic axes or punctual. It may have one center or multiple centers. It may increase the density of constructions in an area or sprawl to surrounding areas. In this study, we try to characterize urban growth at regional and city levels using a set of quantitative measures of spatial metrics. The BU areas extracted from Landsat images were put into FRAGSTATS to generate spatial metrics.

In FRAGSTATS, we calculated six parameters to quantify the urban footprint at each time: class area (CA) or absolute urban area, percentage of landscape (PLAND), number of patches (NP), largest patch index (LPI), landscape shape index (LSI), and normalized landscape shape index (NLSI). The CA metric is the total BU area and the PLAND is its percent cover in a specific area. They describe the growth of urban areas at different time frames. The NP is a measure of fragmentation of urban areas. The eight-neighbor rule was used in delineating patches. An increase of NP indicates the conversion of nondeveloped land into BU areas in suburbs and rural areas, where BU areas occur as isolated patches. The LPI represents the percentage of an urban core area as a proportion of total urban land. It quantifies the percentage of total landscape area comprising the largest patch. It increases when urban areas become more aggregated into urban cores. The LSI provides a measure of class aggregation or clumsiness, which increases as the patch type becomes more disaggregated. The NLSI rescales LSI for each class to give a simplified measure of class aggregation. These metrics are further described in Table 3.

In addition to the analysis using the complete spatial extent in each city, spatial patterns at local scales can be illuminated via zonal analysis. A zonal-based parameter, BU density (BD), is 
Lu et al.: Monitoring bidecadal development of urban agglomeration with remote sensing images...

Table 3 Spatial metrics used in this study.

Metric Description

Class area

Percentage of landscape

Number of patches

Largest patch index

Landscape shape index

Normalized landscape shape index
The sum of the areas $\left(\mathrm{m}^{2}\right)$ of all urban patches divided by 10,000 (to convert to hectares); that is, total urban area in the landscape

The sum of the areas $\left(\mathrm{m}^{2}\right)$ of all patches of the corresponding patch type, divided by total landscape area $\left(\mathrm{m}^{2}\right)$, multiplied by 100 (to convert to a percentage)

The number of patches of the corresponding patch type (class)

The area $\left(\mathrm{m}^{2}\right)$ of the largest patch of the corresponding patch type divided by total urban area $\left(\mathrm{m}^{2}\right)$, multiplied by 100 (to convert to a percentage)

The total length of edge (or perimeter) involving the corresponding class, given in number of cell surfaces, divided by the minimum length of class edge (or perimeter) possible for a maximally aggregated class, also given in number of cell surfaces, which is achieved when the class is maximally clumped into a single, compact patch

The total length of edge (or perimeter) involving the corresponding class, given in number of cell surfaces, minus the minimum length of class edge (or perimeter) possible for a maximally aggregated class, also given in number of cell surfaces, divided by the maximum minus the minimum length of class edge

also employed to characterize spatiotemporal urban sprawl. ${ }^{23}$ It is the ratio of the BU area to the total area of the particular zone. BD values of each zone are calculated using ArcGIS 9.3.

\section{Results and Discussion}

\subsection{BU Index and Urban Development Mapping}

To demonstrate the results of BU area detection, Fig. 2 shows an example subset of the ETM+ data for the metropolitan area of Tangshan in 2000. The urbanized city's extent, the linear axial growth, and the existing satellite towns are clear in the subset image [Fig. 2(a)] and the build-up index [Fig. 2(b)]. The extracted results are illustrated in Fig. 2(c). Due to the spectral similarity of bare soil and BU areas in the TM/ETM+ data, it is difficult to delineate the two land cover types. High classification confusion error also exists under complex topographic conditions. To achieve a precise depiction, we constrained our analysis to plain areas.

We implemented a comparative analysis of BU area extraction results in different periods to monitor and analyze land cover changes in the Jing-Jin-Tang area. The urban land map in Fig. 3 reveals the urban footprints and their spatiotemporal evolution since the 1990s, and shows the evolution patterns of the Jing-Jin-Tang urban agglomerations in the past two decades. From this figure, we can visualize the spatial expansion of each city, the increase of satellite towns, and the growth of traffic infrastructure all over the study area. The traffic network grew rapidly during this period. The Jing-Jin-Tang highway, the first highway approved by the Chinese government, was built between 1984 and 1995. The eight-lane Jing-Jin highway (135-km long) and highspeed railway (120-km long) between Beijing and Tianjin began to construct in 2005 and was finished in 2008. These new infrastructures dramatically promoted regional development and urbanization in this area.

For each city, a dense urban core was located in the center in the early 1990s, surrounded by smaller urban centers of counties and towns under each city municipal administration. Beijing is 

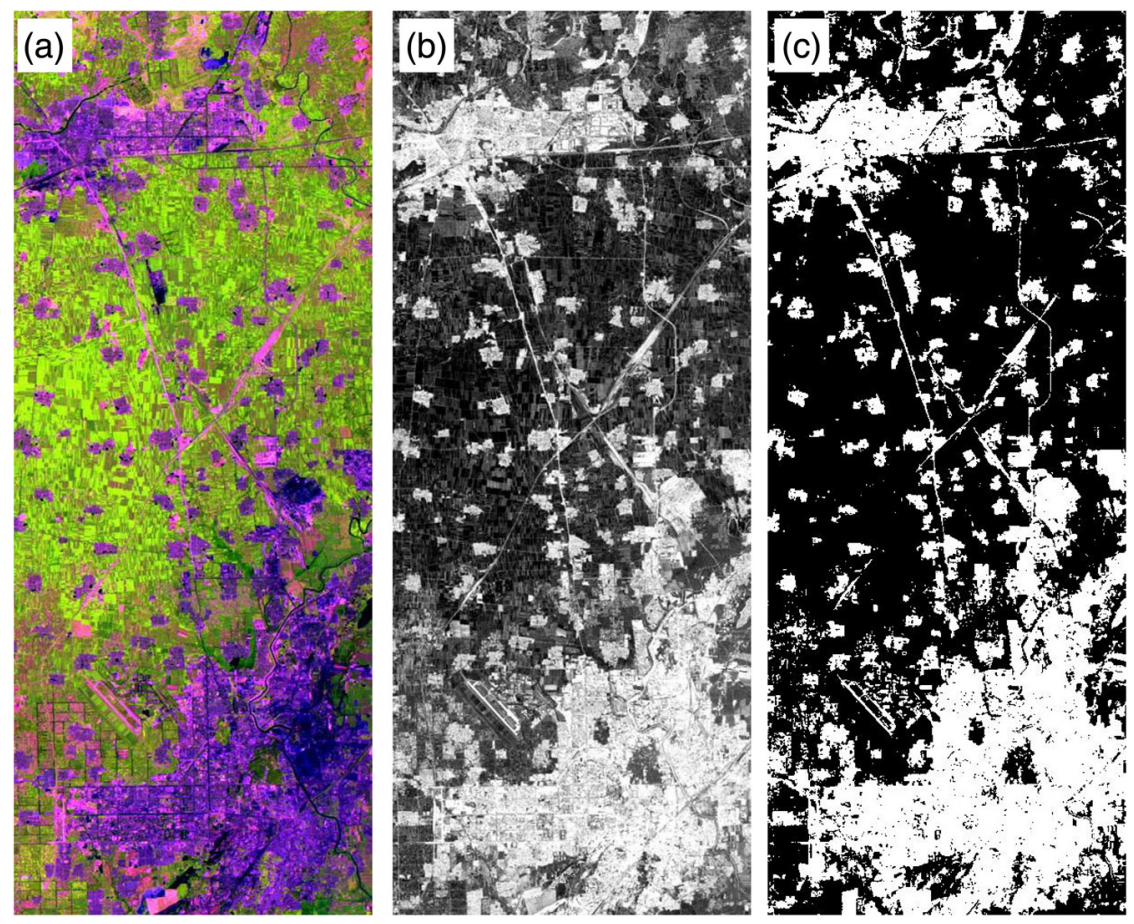

Fig. 2 Built-up (BU) area extraction from an example Landsat image. (a) Subset of Landsat ETM+ Bands 5, 4, and 3 displayed in red, green, and blue, respectively, (b) BU index, and (c) BU area extracted.

the most populous city of the three and has the largest urban center. New BU areas, settlements, and infrastructure were developed in the east between 1990 and 2000 and the north and south between 2000 and 2010. It is related to Beijing's "new city building" policy in the corresponding districts and counties. The extension is limited in the west due to the limited land resources in mountainous areas. The metropolitan Tianjin extends along a southeastern axis defined by the Jing-Jin-Tang highway. The east of Tianjin is located in the centric position of Jing-Jin-Tang and also the coastal area. With great geographic advantages, the BNA has been under development as a major economic development zone under the opening-up policies since 1994. Industrial

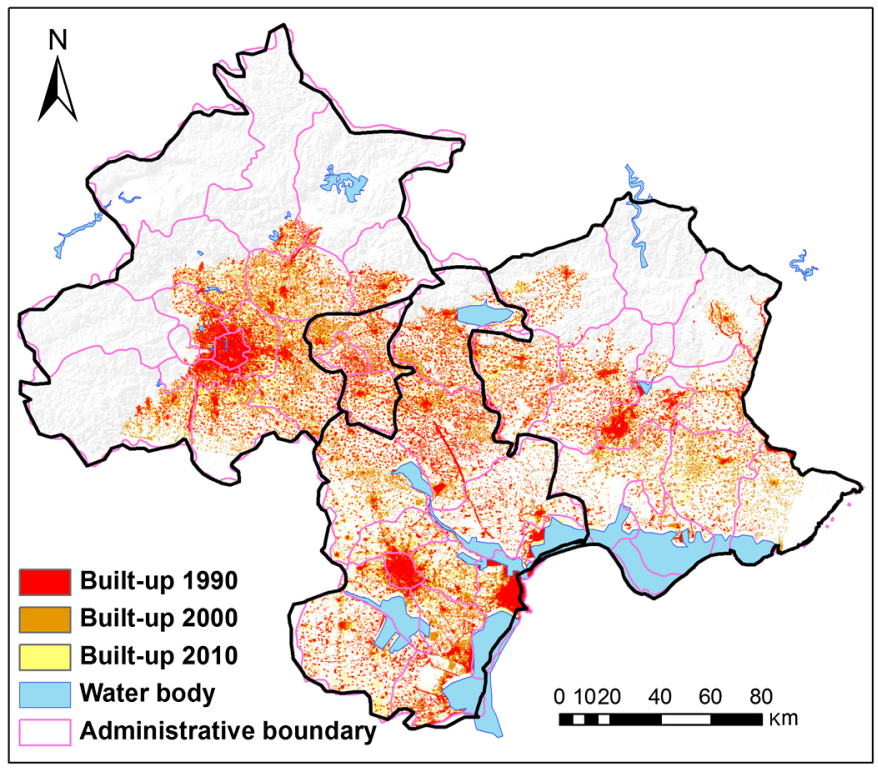

Fig. 3 Expansion of BU areas in the Jing-Jin-Tang urban agglomeration between 1990 and 2010. 
Lu et al.: Monitoring bidecadal development of urban agglomeration with remote sensing images...

districts, commercial districts, airports, and seaports have been built and extended. The gross domestic product grew at a speed of $20.6 \%$ between 1994 and $2010 .{ }^{37}$ The counties in northwestern and southeastern Tangshan also sprawled quickly between 2000 and 2010.

We assessed the accuracy of each BU map with randomly distributed points. Real-time ground data collection is not possible in such a large study area. Alternatively, we collected validation data by visually interpreting the Landsat images since build-up, and nonurbanized areas (mostly agricultural lands in this region) can be easily identified in these 30-m resolution datasets (as shown in Fig. 2). Validation points were also collected from high-resolution imagery such as SPOT5, Ikonos, and QuickBird that were collected in previous studies. For each scene, approximately $1 \%$ of the total pixels, in at least 80 polygons including both "BU" and "not BU" classes, were obtained with $70 \%$ used for threshold optimization and $30 \%$ for accuracy assessment.

The error matrix approach was applied to assess the overall accuracies and two types of classification errors. ${ }^{38}$ The commission error measures the proportion of samples that are classified as a given class but are not actually from that class, and the omission error measures the proportion of samples that are not identified as a given class but are actually from that class. Table 4 shows the estimation of the commission and omission errors, the overall accuracy, and $\kappa$ coefficient for the same year. Since there are only two classes (BU areas and nonurban areas), only the omission and commission errors of BU areas are shown in Table 4. The overall accuracies range from $75 \%$ to $91 \%$ correctly classified pixels. Higher omission errors are observed in small villages and the urban-fringe areas, which are often mixed with nonurbanized areas and could not show the obvious spectral signature of urban areas. High commission errors exist in barren lands in which bare soil has a spectral signature similar to BU areas.

\subsection{Spatial Pattern Analysis at the City Level}

The changes of CA and PLAND indicate that all the cities have experienced rapid urban area expansion since 1990 (Fig. 4). This is driven by social and economic impacts such as population growth, economic development, and infrastructure construction. The CA of Beijing is lower than Tianjin and Tangshan, since only metropolitan areas in southeastern Beijing were urban lands of the Jing-Jin-Tang urban agglomeration in our study (Fig. 3). Meanwhile, the PLAND of Beijing is higher than the other two cities, which indicates the percentage of BU areas in Beijing is highest across the study area. The NP increased in the 1990s and decreased in the 2000s in Beijing [Fig. 4(a)], indicating the amalgamation between satellite towns (and the urban core as well) and individual urbanized patches in the 2000s. The continuous NP increased in Tianjin [Fig. 4(b)] and Tangshan [Fig. 4(c)] in 2000 and 2010, revealing the growth of new towns in suburban areas. The slight increase of LPI in Beijing and Tianjin implies that their urban cores have continuously comprised more urban land in the past three decades. In Tangshan, the LPI is comparatively stable. The urban growth occurs not only in the urban core but also in counties at similar speeds. The slight decrease of LSI and NLSI indicates that Beijing is becoming more aggregated and a homogeneous urban patch has formed from 2000 to 2010. On the contrary, the increase of LSI in Tianjin and Tangshan implies that they are becoming more decentralized.

\subsection{Zonal Analysis of Spatial Patterns at the County Level}

A BU density analysis of each subdivision was carried out for the period of 1990 to 2010. In each city, the highest BU density exists in the metropolitan area or the center of the city (Fig. 5). The

Table 4 Accuracy assessment of the resultant BU maps.

\begin{tabular}{lcccc}
\hline \hline Images & Omission error (\%) & Commission error (\%) & Overall accuracy (\%) & $\kappa$ coefficient \\
\hline TM/ETM+ & 13.33 to 21.43 & 26.67 to 35.00 & 75.00 to 91.35 & 0.50 to 0.69 \\
\hline \hline
\end{tabular}



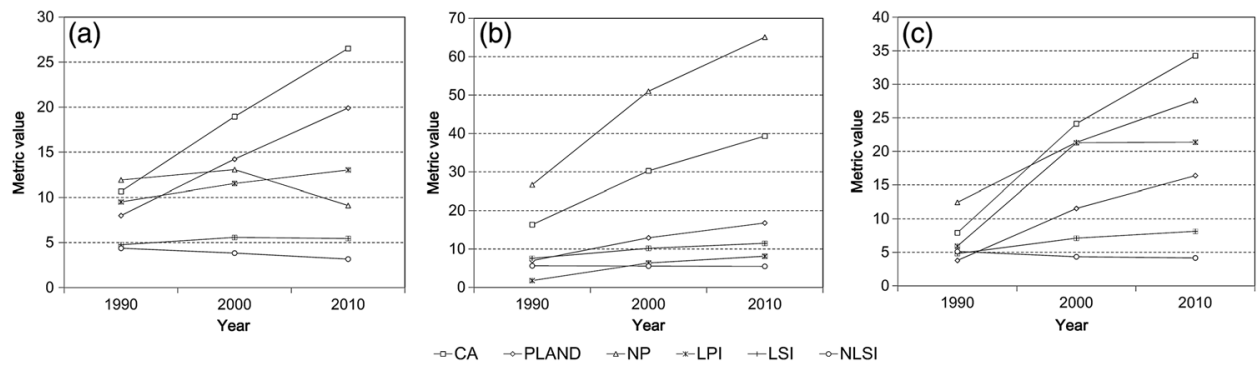

Fig. 4 Fluctuation of six spatial metrics between 1990 and 2010 in Beijing (a), Tianjin (b), and Tangshan (c).

BDs of the metropolitan areas of Beijing, Tianjin, and Tangshan have different growth rates. For Beijing and Tianjin, the BD increased from 0.88 and 0.77 to higher than 0.9 in the past 20 years. For Tangshan, the BD only increased from 0.28 to 0.55 . Tianjin grew more rapidly in the $1990 \mathrm{~s}$ and Tangshan in the 2000s. As municipalities, the construction and development of the metropolitan Beijing and Tianjin started in the early 1980s and became almost fully developed at the end of 1990. Tangshan, like many medium-sized cities in China, is still enduring a development process with an accelerating pace.

Three of the four urban districts in Beijing - Chaoyang, Fengtai, and Haidian-had BD values above 0.4 in 2010. The BDs of the four urban districts of Tianjin were between 0.3 and 0.4 Although located in the outskirts, Tanggu and Hangu had a higher BD than other suburban districts. They are near the coastal zone in the east of Tianjin and are part of the BNA. The counties between Beijing and Tianjin (Xianghe, Sanhe, and Dachang counties) also had a $\mathrm{BD}$ above 0.4. Population and BU area increased in these counties, partly caused by the residential migration from Beijing. Many people who work in Beijing choose to live in these counties to avoid the high living expenses. Among all the counties in Tangshan, Yutian, Luan, Luannan, and Fengrun were the densest BU areas, with a BD between 0.2 and 0.3. They are located in the plain area.

The combination of remote sensing and spatial metrics analysis provides a promising method for studying urban change. However, because of the spectral mixture problem and visually selected thresholds between urban and nonurban areas in mapping process, the accuracy of the proposed method needs to be improved. ${ }^{39}$ Classification techniques combining spectral, spatial, and temporal information of remote sensing images can be developed to improve the classification accuracy. Moreover, satellite data at different spatial scales captured the urban growth footprints with different details. With the increasing availability of satellite observations, the integration of multisource remote sensing data is promising for better delineation of urban extent.

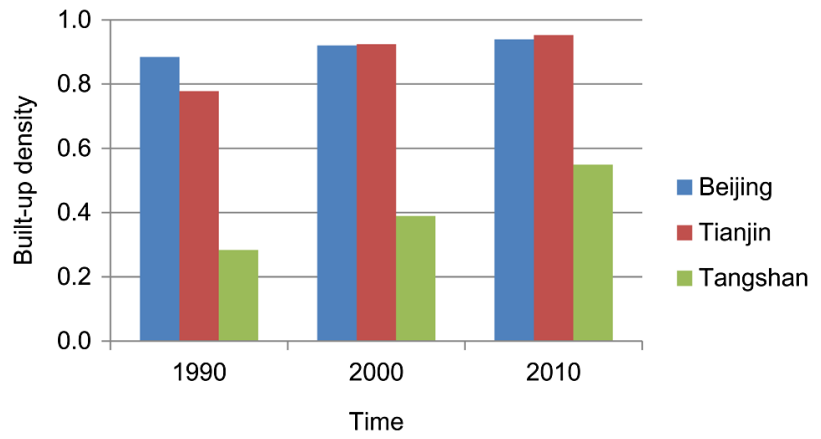

Fig. 5 BU density (BD) variation in metropolitan area of Beijing, Tianjin, and Tangshan between 1990 and 2010. 


\section{Conclusions}

This study adopted an integrated approach of multitemporal remote sensing and multiscale spatial metric analysis to characterize the dynamics of urban expansion in the Jing-Jin-Tang urban agglomeration in the past 20 years (1990-2010). The results from three sets of Landsat imagery show that the BU area in this region has undergone a substantial increase, especially in the late 1990s to early 2000s. Although the three cities, Beijing, Tianjin, and Tangshan, each had a rapid expansion of BU areas, our results reveal their different development patterns. The NP, LPI, and LSI were used to understand the total urban growth patterns, and BD was used to analyze the development of different zones. BU land in Tianjin and Tangshan has been disaggregating with the increasing number of satellite towns in the suburban area, while those of Beijing, the capital city of China, have been aggregating to a more homogeneous urbanized region since the 2000s. Due to their suitability for human settlement and the government policies of economic development, the suburban counties located in plain areas and coastal districts of Tianjin maintain relatively high BU densities.

Multitemporal Landsat imagery proved to be effective in the study of urban agglomeration expansion. In the future, urban growth patterns of different regions can be analyzed and compared using multisource satellite data. The spatial information is useful for decision makers and urban planners and benefits regional sustainable development.

\section{Acknowledgments}

This research was supported by the Major International Cooperation and Exchange Project of the Chinese National Natural Science Foundation "Comparative study on global environmental change using remote sensing technology" under Grant No. 41120114001 and the 973 project 2009CB723906 "Earth observation for sensitive factors of global change: mechanisms and methodologies" from the Ministry of Science and Technology of China.

\section{References}

1. C. Weber, "Remote sensing data used for urban agglomeration delimitation," in Remote Sensing and Urban Analysis, M. J. Barnsley, Ed., pp. 155-167, Taylor \& Francis, London (2001).

2. National Bureau of Statistics of China, China Population Statistics Yearbook 2005, China Statistics Press, Beijing (2005).

3. X. Liu et al., "Simulating urban expansion using an improved SLEUTH model," J. Appl. Remote Sens. 6(1), 061709 (2012), http://dx.doi.org/10.1117/1.JRS.6.061709.

4. K. He, H. Huo, and Q. Zhang, "Urban air pollution in China: current status, characteristics, and progress," Ann. Rev. Energy Environ. 27, 397-343 (2002), http://dx.doi.org/10.1146/ energy.2002.27.issue-1.

5. J. Chen, "Rapid urbanization in China: a real challenge to soil protection and food security," Catena 69(1), 1-15 (2007), http://dx.doi.org/10.1016/j.catena.2006.04.019.

6. C. Y. Ji et al., "Monitoring urban expansion with remote sensing in China," Int. J. Remote Sens. 22(8), 1441-1455 (2001), http://dx.doi.org/10.1080/01431160117207.

7. F. Yuan et al., "Land cover classification and change analysis of the Twin Cities (Minnesota) Metropolitan Area by multitemporal Landsat remote sensing," Remote Sens. Environ. 98, 317-328 (2005), http://dx.doi.org/10.1016/j.rse.2005.08.006.

8. A. E. Huzui, A. Abdelkader, and I. Patru-Stupariu, "Analyzing urban dynamics using multitemporal satellite images in the case of a mountain area, Sinaia (Romania)," Int. J. Digital Earth 6(6), 563-579 (2013), http://dx.doi.org/10.1080/17538947.2011.642901.

9. X. Yu et al., "Multi-temporal remote sensing of land cover change and urban sprawl in the coastal city of Yantai, China," Int. J. Digital Earth 6(S2), 137-154 (2013), http://dx.doi.org/ 10.1080/17538947.2011.653995.

10. Q. Weng, "Land use change analysis in the Zhujiang Delta of China using satellite remote sensing, GIS and stochastic modeling," J. Environ. Manage. 64(3), 273-284 (2002), http:// dx.doi.org/10.1006/jema.2001.0509. 
Lu et al.: Monitoring bidecadal development of urban agglomeration with remote sensing images...

11. P. Griffiths et al., "Mapping megacity growth with multi-sensor data," Remote Sens. Environ. 114(2), 426-439 (2010), http://dx.doi.org/10.1016/j.rse.2009.09.012.

12. M. Pesaresi et al., "Toward global automatic built-up area recognition using optical VHR imagery," IEEE J. Sel. Top. Appl. Earth Observ. 4(4), 923-934 (2011), http://dx.doi.org/10 .1109/JSTARS.2011.2162579.

13. I. J. A. Callejas et al., "Relationship between land use/cover and surface temperatures in the urban agglomeration of Cuiabá-Várzea Grande, Central Brazil,” J. Appl. Remote Sens. 5(1), 053569 (2011), http://dx.doi.org/10.1117/1.3666044.

14. H. Taubenböck et al., "Monitoring urbanization in mega cities from space," Remote Sens. Environ. 117, 162-176 (2012), http://dx.doi.org/10.1016/j.rse.2011.09.015.

15. X. M. Li, W. Q. Zhou, and Z. Y. Ouyang, "Forty years of urban expansion in Beijing: what is the relative importance of physical, socioeconomic, and neighborhood factors?," Appl. Geogr. 38, 1-10 (2013), http://dx.doi.org/10.1016/j.apgeog.2012.11.004.

16. L. Gueguen et al., "Urbanization detection by a region based mixed information change analysis between built-up indicators," IEEE J. Sel. Top. Appl. Earth Observ. 6(6), 2410-2420 (2013), http://dx.doi.org/10.1109/JSTARS.2013.2246547.

17. M. Herold et al., "Spectrometry for urban area remote sensing-development and analysis of a spectral library from 350 to 2400 nm," Remote Sens. Environ. 91(3-4), 304-319 (2004), http://dx.doi.org/10.1016/j.rse.2004.02.013.

18. B. Guindon, Y. Zhang, and C. Dillabaugh, "Landsat urban mapping based on a combined spectral-spatial methodology," Remote Sens. Environ. 92(2), 218-232 (2004), http://dx.doi .org/10.1016/j.rse.2004.06.015.

19. Q. Zhang et al., "A semiautomatic segmentation procedure for feature extraction in remotely sensed imagery," Comput.Geosci. 31(3), 289-296 (2005), http://dx.doi.org/10.1016/j.cageo .2004.10.003.

20. J. G. Masek, F. E. Lindsay, and S. N. Goward, "Dynamics of urban growth in the Washington DC Metropolitan Area, 1973-1996, from Landsat observations," Int. J. Remote Sens. 21(18), 3473-3486 (2000), http://dx.doi.org/10.1080/014311600750037507.

21. Y. Zha, J. Gao, and S. Ni, "Use of normalized difference built-up index in automatically mapping urban areas from TM imagery," Int. J. Remote Sens. 24(3), 583-594 (2003), http:// dx.doi.org/10.1080/01431160304987.

22. C. He et al., "Improving the normalized difference built-up index to map urban built-up areas using a semiautomatic segmentation approach," Remote Sens. Lett. 1(4), 213-221 (2010), http://dx.doi.org/10.1080/01431161.2010.481681.

23. M. Herold, C. N. Goldstein, and C. K. Clarke, "The role of spatial metrics in the analysis and modeling of urban land use change," Comput. Environ. Urban Syst. 29(4), 369-399 (2005), http://dx.doi.org/10.1016/j.compenvurbsys.2003.12.001.

24. H. Taubenbock et al., "Urbanization in India-spatiotemporal analysis using remote sensing data," Comput. Environ. Urban Syst. 33(3), 179-188 (2009), http://dx.doi.org/10.1016/j .compenvurbsys.2008.09.003.

25. R. V. O’Neill et al., "Indices of landscape pattern," Landscape Ecol. 1(3), 153-162 (1988), http://dx.doi.org/10.1007/BF00162741.

26. M. Herold, C. N. Goldstein, and C. K. Clarke, "The spatiotemporal form of urban growth: measurement, analysis and modeling," Remote Sens. Environ. 86(3), 286-302 (2003), http://dx.doi.org/10.1016/S0034-4257(03)00075-0.

27. H. M. Pham and Y. Yamaguchi, "Urban growth and change analysis using remote sensing and spatial metrics from 1975 to 2003 for Hanoi, Vietnam," Int. J. Remote Sens. 32(7), 1901-1915 (2011), http://dx.doi.org/10.1080/01431161003639652.

28. K. McGarigal et al., "FRAGSTATS: Spatial Pattern Analysis Program for Categorical Maps," Computer software program produced by the authors at the University of Massachusetts, Amherst, 2002 http://www.umass.edu/landeco/research/fragstats/fragstats .html (20 August 2013).

29. United Nations, World Urbanization Prospects the 2007 Revision, United Nations Department of Economic and Social Affairs/Population Division, New York (2008).

30. National Bureau of Statistics of China, Bulletin of the Sixth National Population Census (No. 2), Beijing (2011). 
31. National Bureau of Statistics of China, Bulletin of the Fifth National Population Census (No. 2), Beijing (2001).

32. National Bureau of Statistics of China, Bulletin of the Fourth National Population Census (No. 2), Beijing (1990).

33. National Aeronautic Space Administration, Landsat Data Continuing Mission, http://ldcm .nasa.gov/index.htm (23 September 2011).

34. M. A. Wulder et al., "Landsat continuity: issues and opportunities for land cover monitoring," Remote Sens. Environ. 112(3), 955-969 (2008), http://dx.doi.org/10.1016/j.rse.2007 .07 .004 .

35. R. Richter, "A spatially adaptive fast atmospheric correction algorithm," Int. J. Remote. Sens. 17(6), 1201-1214 (1996), http://dx.doi.org/10.1080/01431169608949077.

36. C. Wang, B. Zhou, and H. L. Palm, "Detecting invasive Sericea Lespedeza (Lespedeza cuneata) in mid-Missouri pastureland using hyperspectral imagery," Environ. Manage. 41(6), 853-862 (2008), http://dx.doi.org/10.1007/s00267-008-9092-8.

37. Bureau of Statistics of Tianjin Binhai New Area, Tianjin Binhai New Area Statistical Yearbook, Statistics Press, Beijing (2010).

38. R. G. Congalton, "A review of assessing the accuracy of classifications of remotely sensed data," Remote Sens. Environ. 37(1), 35-46 (1991), http://dx.doi.org/10.1016/0034-4257 (91)90048-B.

39. N. T. Son et al., "Urban growth mapping from Landsat data using linear mixture model in Ho Chi Minh City, Vietnam,” J. Appl. Remote Sens. 6(1), 063543 (2012), http://dx.doi.org/ 10.1117/1.JRS.6.063543.

Linlin Lu is an associate professor at the Institute of Remote Sensing and Digital Earth, Chinese Academy of Sciences (RADI, CAS). She received her PhD degree from the Institute of Remote Sensing Applications, CAS, in 2009. Since then she has been working as a researcher at the Key Laboratory of Digital Earth Science of RADI, CAS. Her research interests include image classification and time series analysis applied to human settlement mapping and phenology.

Huadong Guo is director-general of RADI, CAS, an academician of CAS, and a fellow of the Academy of Sciences for the Developing World. He has over 30 years of experience in remote sensing, focusing on radar remote sensing, and digital Earth. He has published more than 300 papers and 15 books, and is the principal awardee of 13 national and CAS prizes.

Cuizhen Wang received her MS and $\mathrm{PhD}$ degrees from the Institute of Remote Sensing Applications, CAS, in 1996 and 1999, and the PhD degree from Michigan State University in 2004. After graduation, she joined the Department of Geography at University of Missouri-Columbia in August 2004. Since 2013, she has become an associate professor in the Department of Geography, University of South Carolina, USA. Her primary research interests are bioenvironmental remote sensing, GIS, and spatial analysis.

Martino Pesaresi graduated in town and regional planning from IUA Venice, 1992. Since 2004, he has been with Global Security Unit of the Institute for the Protection and Security of the Citizen, Joint Research Centre, European Commission (EC JRC) based in Ispra, Italy. Since September 2007, he has been leading the Geospatial Information Analysis for the Global Security and Stability (ISFEREA) team of the same JRC Institute.

Daniele Ehrlich received the BS degree in forestry in 1984 from University of Padova, Italy, and the $\mathrm{PhD}$ degree from University California at Santa Barbara in 1992. He is a senior staff member of the EC JRC. He has over 20 years of experience in remote sensing and GIS applied to a variety of disciplines. His current research focuses on quantifying the extent and the dynamics of settlements using high-resolution satellite imagery. 